\title{
Financial Responsibilisation and the Role of Accounting in Social Work: Challenges and Possibilities
}

\author{
Danny S. L. Chow (1) ${ }^{1, *,+}$, David Greatbatch ${ }^{2}$ and \\ Enrico Bracci ${ }^{3}$
}

\footnotetext{
${ }^{1}$ The York Management School, University of York, Freboys Lane, York, YO10 5GD, UK

${ }^{2}$ Durham University Business School, Mill Hill Lane, Durham, DH1 3LB, UK

${ }^{3}$ Department of Economics, University of Ferrara, Via Voltapaletto 21, 44121, Ferrara, Italy

*Correspondence to Danny Chow, The York Management School, University of York, Freboys Lane, York YO10 5GD, UK. E-mail: dannychow@me.com

${ }^{\dagger}$ This address is valid from 1 August 2019 onwards.
}

\begin{abstract}
Accounting provides a distinctive conceptual lens to analyse how neo-liberal reforms in the public sector operate. Despite this, appreciation of the significance of accounting as a key neo-liberal instrument of organisational change is only embryonic in social work research. Against this background, this article presents the findings of an empirical study, conducted across children's services departments at three English councils, which illuminates how neo-liberal policies inculcate financial responsibilities in social work by examining the microprocesses surrounding the application and usage of accounting techniques. The instillation of neo-liberal values that underpin the use of accounting in social work privileges economic efficiency over those emphasising collectivism and organisational resilience. The extent to which accounting has been embraced appears mixed, however, with managers supportive of neo-liberal values and techniques, but frontline practitioners are more circumspect. Another unintended but emancipatory potential reflects the opportunities for social work professionals to reassert their epistemological claims by reshaping accounting with social work values. However, such outcomes remain a distant possibility, whilst managerialism retains its stranglehold on social work. This study raises awareness for the need not only to be cognizant of but also to critically evaluate accounting's role across all areas of social work.
\end{abstract}

Keywords: accounting, financial responsibility, governmentality, neo-liberal, social work

Accepted: April 2019 


\section{Introduction}

Accounting led neo-liberal reforms continue to exert an enduring impact on the public sector in many countries despite their advent more than three decades ago. Hood (1991) notes that such reforms signal a significant transformation in the ethos or values that underpin the public sector, where economic efficiency is prioritised over other values such as collectivism (honesty, fairness and mutuality) and resilience (reliability, robustness and adaptability). Few areas of the public sector remain untouched by such reforms, and social work is no exception.

The impact of neo-liberal reforms on social work has been, over a long period, extensively debated in the literature by both academics and practitioners (e.g. Parton, 1994; Harris, 2003; Ferguson, 2007; Garrett, 2009; Harris and White, 2009; Rogowski, 2010, 2011, 2012; Cummins, 2018). Underpinning neo-liberal reforms is a dependence on accounting as a system enabling behaviour regulation, colloquially known as 'accountingisation'. According to Hood (1995), this term was first coined by Power and Laughlin (1992) to reflect an overwhelming emphasis on cost measurement and the use of management accounting techniques developed in the private sector. Extant research, which is reviewed in the next section, firmly locates accounting at the heart of many neo-liberal reforms in the public sector.

Hopwood (1983) alerts us to the reality that accounting is a socially constructed practice, despite its appearance as a scientific method of objective measurement. For instance, Llewellyn (1998a, 1998b) illustrates how accounting is used in social work to implement policies favouring economic efficiency. Such reforms realigned organisational responsibilities and in the process breached or challenged professional enclosures that emphasised professional autonomy and discretion in social work practice (Llewellyn, 1998a; see also Rogowski's (2010) discussion of bureau-professional power in social work). In studies on the role of accounting in enabling the personalisation of social work, Bracci and Llewellyn (2012), Bracci (2014), Junne and Huber (2014) and Junne (2018) all illustrated how governable individuals are constituted through a combination of entrepreneurial autonomy and disciplinary control.

These studies powerfully demonstrate that accounting can provide an insightful conceptual lens for analysing how neo-liberal reforms operate. However, appreciation of accounting as a key neo-liberal instrument of organisational change is only embryonic in social work research. Consequently, despite long-standing debates over the growing reliance on accounting for management control and audit (Munro, 2004), the increasing significance of information systems replacing narratives as way of thinking and operating (Parton, 2008), managerialism (Harris and White, 2009; Rogowski, 2010) and the marketisation of social work 
provision (Ferguson, 2007; Rogowski, 2012), there is still a lack of clarity over specific roles that accounting plays in social work practice. There is therefore a need to better understand, from a microprocessual perspective, how accounting operates in social work to (re-) constitute the way in which social work is organised and managed.

This empirical study, based on interviews with social workers, managers and accountants across three councils in England, examines how financial responsibilities are inculcated through expanding use of accounting techniques and concepts. The article is structured as follows. Section 'Role of accounting in neo-liberal reforms in constituting financial responsibilities' reviews the literature on the role of accounting in constituting financial responsibilities in public sector organisations. Section 'Context and methods' describes the context and methodology used. Section 'Findings' presents the article's key findings on a thematic basis. Finally, Section 'Concluding thoughts' presents our conclusions.

\section{Role of accounting in neo-liberal reforms in constituting financial responsibilities}

Accounting-led neo-liberal reforms are seen as a way to cope with growing concerns over financial resources in the public sector through wholesale transformations based on values that prioritise economic efficiency. Such transformations focus on making public sector professionals more responsible for the decisions they take and the financial implications that follow. This can be observed when neo-liberal rhetoric is used to support the case for economic efficiency in social work. For instance, Rivest and Moreau (2015) point to the constitution of social workers as financially responsible individuals through discourses on empowerment; Llewellyn (1998b) describes how the use of devolved financial budgets facilitate the ascription of financial responsibilities down the organisational hierarchy; and Junne and Huber (2014) observe how norms of appropriate financial behaviour are being developed through experimentation with personal budgets.

The ascriptions of financial responsibilities can be broad-ranging in their implementation at an organisational level. For instance, Miller and Rose (1990) illuminate how these new responsibilities bring about material change, with the introduction of management control systems to regulate organisational behaviour, the use of accounting concepts such as cost-benefit analysis in decisions of rationing (e.g. gatekeeping) and more broadly, a change in core values underpinning the identities of public sector professionals. Whilst Chiapello (2017) notes that a critically oriented accounting literature can sometimes paint such transformations of values in a pejorative manner (e.g. Arnold, 1998; Cooper, 2015), she calls for a rebalancing of research towards more impartial evaluations of 
accounting's role in neo-liberal reforms. Chiapello's arguments chime with a number of studies suggesting that, under the right conditions, accounting can bring about emancipatory outcomes by nurturing entrepreneurial behaviour and self-sufficiency amongst public sector professionals. For example, in Wickramasinghe's (2015) case study of an accounting-inspired organisational change at Sri Lankan hospitals, innovative staff took advantage of their newly acquired autonomy to adapt ideas from managerial accounting to break free from the constraints imposed by methods of administration inherited from the colonial government that were deemed to be outdated. However, Rogowski (2010, p. 159) is more sceptical, arguing that the reliance on accounting as a tool of instrumental rationalism fails to account for more informal and relationship-based approaches to social work practice. In the same vein, Parton (2008) concludes that an information systems approach (on which accounting is based) is unable to capture thoughts of a more reflective and critical nature.

So, how does the use of accounting facilitate the implementation of neo-liberal ideas and values to transform the organisation? At a structural level, the adoption and implementation of accounting techniques in the public sector (social work included) can be seen to embody a system of measurement encapsulated by Foucault's concept of biopower (Parton, 1994; Chiapello, 2017; Raffnsøe et al., 2019). Accounting in this regard is conceived as a system to regulate individuals through the capture of information about their behaviour and characteristics (Miller and Rose, 1990; Parton, 1994). In particular, accounting allows knowledge of geographically dispersed sites to be mobilised and brought home to centres of calculation (Robson, 1992), such as the senior management team. Moreover, Robson (op cit.) also notes that accounting inscriptions have features such as mobility, stability and combinability. These are key elements enabling 'action from a distance' or the exercise of what Foucault refers to as panoptic power, continuously observing the work and actions of individuals. Accounting measurements are also encroaching in areas that were previously considered free from economic relevance (e.g. relationships between professionals and their clients), thereby creating new calculable spaces and objects (Miller and O'Leary, 1987). These new measurements, combined with surveillance, serve as a form of power that can be used both for disciplinary (i.e. compliance or coercion), as well as productive (i.e. self-motivation) purposes.

Information generated by accounting can be used by senior management in public sector organisations to establish new norms and create new possibilities for action by professionals. In their studies of healthcare professions, Kurunmäki (2004) and Wickramasinghe (2015) show how the construction of new freedoms and responsibilities can foster greater support for accounting's role if it is perceived to improve existing ways of doing things. In both of these cases, professionals were 
entrusted with accounting innovations, combining insights on cost behaviour with their own professional (i.e. medical) expertise.

In parallel with the structural changes described, the introduction of accounting-led reforms is also a key contributor to the transformation in the core values that guide professional behaviour through an emphasis on economic efficiency. Older, collectivist approaches to the way in which social work is provisioned is giving way to increasing familiarisation with entrepreneurial ideas (Harris and Unwin, 2009; Rogowski, 2010; Cummins, 2018). For instance, through programmes such as personalisation, which emphasises individualised provision of adult services, citizens are now expected to be responsible for their own care, bearing the risks should things go wrong (Ferguson, 2007; Rivest and Moreau, 2015, p. 1865). For social workers, the individualising and economising effects of neo-liberal reforms pitches those who practice against those who manage (Rogowski, 2011). Social workers who take on managerial roles are perceived by front-line staff to have left behind their professional identity to embrace economic values and become primarily concerned with organisational functioning and survival (ibid.).

It is vital, however, to understand that under neo-liberal reforms, the power to govern is not exercised through coercion but through a complex blend of disciplinary and productive power, which ascribes responsibilities to individuals. The power to (self-) govern through the use of accounting techniques is meant to encourage entrepreneurship and selfsufficiency (Cooper, 2015). Foucault first coined this idea of governing through autonomy as governmentality when analysing the rise of neoliberalism in Western Europe (Raffnsøe et al., 2019, p. 12; Chiapello, 2017). According to Foucault (1991, p. 102), governmentality is defined as:

the ensemble formed by the institutions, procedures, analyses and reflections, the calculations and tactics that allow the exercise of this very specific albeit complex form of power, which has as its target population, as its principal form of knowledge political economy.

The relevance for the analysis of financial responsibilisation in social work is to recognise the discursive nature of governmentality. Change in public sector organisations relies on the 'production, accumulation, circulation and functioning of a discourse' (Foucault, 1982, p. 93). This in turn mobilises technologies of government as a means to normalise the conduct, thought, decisions and aspirations of others (Parton, 1994; Rivest and Moreau, 2015). For example, Llewellyn and Northcott (2005) examine the creation of accounting measurements such as average costs in the British National Health Service (NHS), which enables hospital managers to benchmark their organisation's performance at a national level. Llewellyn and Northcott find that hospitals with higher than 
average costs (defined as a negative deviation from the benchmark) are expected to take corrective action. Norms such as cost benchmarks enable power to be exerted by managers from a distance through the use of surveillance to enforce compliance, coupled with a socialisation process that normalises values of economic efficiency.

In the context of social work, a reliance on accounting techniques is expanding. This is exemplified by the ascription of new financial responsibilities for social workers now expected to manage organisational and institutional resources through budgets. In their studies of how accountability relationships are transformed by individual/personal budgets, Junne and Huber (2014), Bracci (2014) and Junne (2018) find that the increased financial autonomy is tempered by new control mechanisms in the form of user responsibilisation.

Some go further to argue that expectations of emancipatory and productive effects from neo-liberal applications of accounting is naïve, as accounting used this way can also redistribute power in a manner that subjugates individuals (Arnold, 1998; Cooper, 2015). This is because of the ease with which accounting can be converted for use as a method to increase disciplinary control over the workforce. In the context of social work, Rogowski (2011) and Rivest and Moreau (2015) suggested that the emancipatory potential of neo-liberal constructions of entrepreneurial and self-sufficient individuals is limited because autonomy is curtailed and the individual 'governed' through an expansion of their responsibilities. Rogowski (2011), for instance, argues that managers are becoming all powerful on the back of the implementation of neo-liberal practices and that this can lead to the deformation of social work.

The issue then is whether sufficient managerial freedoms and resources are made available to truly enable governance through individual responsibilisation to work properly, especially from a financial standpoint. Some 'strong' professions, such as doctors, have resisted taking on additional responsibilities for managing financial resources in addition to their medical work (Kurunmäki, 2004). However, social work does not have a defined epistemological basis with which to defend against incursions into their professional enclosures (Parton, 1994, p. 30). This point is illustrated by Llewellyn's (1998a) study on adult services in Scotland. She (Llewellyn) traces how professional enclosures are breached though the reconstitution of organisational tasks, where social workers are made responsible not just for decisions on care but also its costs. In her other study on the issues faced by the delegation of budgets to frontline practitioners, Llewellyn (1998b) describes the difficulties for professionals to fully accept and embrace individualised financial responsibilities. Instead, responsibilities were being collectivised within the organisation, as social workers did not want to be personally identified as having made moral judgements that adversely affected the lives of their clients. A further difficulty can be attributed to ambiguous institutional rules on 
how clients' needs should be prioritised to make best use of finite financial resources (Llewellyn, 1998b, p. 303).

In summary, during the 1990 s, costing emerged as a relevant consideration in social work decisions in the UK. Professional enclosures of social workers were challenged, and in some cases breached, as budgets were subsequently used to formalise the incorporation of cost management as part of individual responsibilities, for both practitioners and clients. Although these developments have been examined in studies conducted by accounting scholars, their findings, concepts and theorising have yet to permeate the field of social work. Moreover, the key studies by Llewellyn were undertaken over twenty years ago and, despite the publication of more recent studies, it is still unclear the extent to which the processes she identified have played out. There is therefore a need to both build on the accounting literature within social work research and to expand the number of more contemporary and empirically based studies to examine how the use of accounting has evolved and the extent to which social workers have adapted or resisted its use.

\section{Context and methods}

This study is situated in the context of austerity in the UK public sector, in the immediate aftermath of the global financial crisis. The then incoming Conservative-Liberal Democrat coalition government in 2010 provided fertile ground for investigating the instillation of new political rationalities. The study focused on three English local government children's services departments. One of these-Deningford council (all councils and individuals are anonymous)—operates in a largely suburban environment over a large geographic area. In contrast, the othersWarbridge and Mexberry councils-operate within large metropolitan conurbations with significantly smaller geographic areas but much denser populations when compared with Deningford.

Both Deningford and Warbridge experienced significant reductions in their budgets post-2010. For example, Warbridge suffered an approximate 25 per cent reduction on their general funded expenditure (including grant reductions), while the head of social work at Deningford, Helen, described the savings her children's services department was required to make as 'huge'. Although the other social work department (Mexberry) did not at the time of our visit experience significant cuts (yet) in their budget, they were challenged by their council to work in a more efficient way and demonstrate value for money. At Deningford and Mexberry, the main financial pressures are from the high costs of rehousing and safeguarding vulnerable children taken into the council's care, as they form a substantive proportion of the council budget for 
children's services. Warbridge had, following major cuts, agreed to a broad three-year spending programme with the council. A list of savings targets in specific areas was produced, which was monitored on a monthly basis as part of the in-year budget monitoring process and future years' process.

We conducted sixteen semi-structured face-to-face interviews with social work professionals across the three councils in 2012. The lead author received clearance from their departmental ethics committee. Interviewees were selected, using purposive sampling, for involvement with accounting reforms in their respective organisations. Their formal roles included heads of service, middle managers, accountants and front-line practitioners. Each interview lasted on average an hour, and all participants provided written or verbal consent. The interviews were recorded, and transcriptions were subsequently sent to participants for comments and corrections. Using an inductive analytical approach, we identified key themes in the interviews and considered where different groups have contrasting views and where there is consensus.

\section{Findings}

\section{Rationalising the need for financial responsibilities}

Core neo-liberal doctrines stress discipline and economic efficiency, underpinned by the ascription of financial responsibilities to individuals and/or groups (Llewellyn, 1998b). The outcome is a greater usage of devolved budgeting and prioritisation of the bottom line (Hood, 1995, p. 96). Practitioners who are ascribed budgetary responsibilities have to juggle financial, emotional and regulatory care elements when making judgments. Such dynamics were clearly present in all three social work departments we visited, with managers expecting front-line practitioners to unequivocally embrace financial responsibility through the ownership of cost centres, as a head of social work pointed out:
unless we own the finance and the responsibility for it we'll never take it seriously [if social work managers] are not held to account for it, they have no concerns at all about money ... every team manager is responsible for a cost centre; every children's home manager is responsible for their cost centre and they are held to account for at that overspending amount [sic]." (Deningford: Helen; text in [.] added for clarity here and in subsequent interview quotes)

These rationalisations illustrate how neo-liberal values and discourses can transform the way in which managers and practitioners conceive of 
the 'collective' financial resource, moving away from notions of shared burdens across society to individualised responsibilities to economise and protect public monies. In other words, the prudent management of costs is believed to improve social work practice through the conservation of resources, as a senior manager explained.

I'm a member of the public, it is my money, and I need to be responsible and accountable for it ... the budget monitoring is necessary (Mexberry: William).

Individuals who espoused such views were often also those who had taken on management roles and/or were being made 'responsible' for budgets. Like the practitioners studied by Rogowski (2011), those who had moved into managerial roles embraced a more organisation-centric perspective. In doing so, however, they were perceived by some colleagues to have left behind their professional 'identity' as front-line practitioners who put their clients first. These individuals, in their role as managers, served as advocates for neo-liberal change within their organisations. A manager with accounting responsibilities explained how this change is translated into practice, through new training requirements on financial management:

if you become a social worker ... your [induction will include training on the] council's budget ... because a lot of social workers would generally have no understanding of the amount of money ... or ... how we monitor budgets ... we would talk about what the general expectation around their role and the budget setting process, how they could help, what we would send them on a monthly basis, what we expected from them and how they could come to us for any help if they needed i (Deningford: Hugh)

Our interviews indicated that the organisational embrace of accounting not only endorses values of economic efficiency but also entrenches it through responsibilisation. For instance, managers in the three social work departments argue that running costs need to be carefully managed through the implementation of accounting techniques for organisational survival. In contrast, the maintenance of older, collectivist instincts that rely more on professional judgement and discretion were made less welcome. The following quote from a head of social work illustrates the threat of exclusion used in organisational discourse, as practitioners were coerced into accepting the need for more financial and nonfinancial responsibilities:

If you don't want to be accountable, if you don't like your practice being audited and checked and your performance monitored it's no good coming here because this is our approach to practice (Deningford: Helen) 
The tone of this threat was softened by a team manager in the same department, who rhetorically framed it as a necessary means of protecting the practice of client-facing social work:

\begin{abstract}
all the parts of the ... council have suffered significant reductions as a result of budget pressures but this service [mandating that families are allowed contractual contact time with children after legal separation] has come off quite lightly. That puts an additional pressure on managers to ... meet their budget targets ... because that is ... politically problematic if [some social workers] aren't doing that when [others] are trying desperately to protect some of this front-line service provision. (Deningford: Francis)
\end{abstract}

In summary, the socialisation process observed in the three departments was built on a discourse of compromise, with social workers expected to empathise and identify with the changing environment they found themselves in. Here, new moralities centred on the need to improve stewardship of public monies were instilled, and those that resist the intensification of economic efficiency values were threatened with exclusion.

\title{
Discourses conceptualising economic efficiency in social work practice
}

Previous research (e.g. Llewellyn 1998a, 1998b) has shown that discourses on economic efficiency in the context of social work materialises through the utilisation and adaptation of specific accounting concepts such as cost-benefit analysis (CBA) and value for money (VFM) by social work practitioners. CBA is an extensively used concept in accounting aimed at objectively comparing the actual and future cost and benefit of alternative decisions. Value for money is similar to CBA, but draws attention to more subjective definitions of benefits to also include non-monetary outcomes when policy choices are ranked. Once these ideas are implemented more widely in social work, accounting concepts become more engrained into the psyche of social work managers (e.g. Llewellyn, 1998a). In other words, management is embracing the use of accounting to deal with reprioritised objectives such as cost containment-with the balancing of costs and care now being the requisite mode of operations.

CBA is used to evaluate different trade-offs that take into consideration not only professional values in social work but also financial resources. In this study, for instance, practitioners incorporated these principles in their adoption (and adaptation) of a new evaluator tool promoted by the Department of Health (England): The Social Return 
on Investment (SROI). The SROI attempts to quantify subjectively defined benefits and compare it with financial costs incurred (Millar and Hall (2013) and Hall and Millo (2018) are useful primers on SROI). A team manager offered an illustration of how SROI was interpreted in practice:

... if we could prevent two babies from becoming accommodated as a result of the support we were offering to those families, we knew it would cost this amount in the care proceedings, this amount for a local authority foster placement ... therefore we could recoup the costs for setting up the project within a year easily. (Deningford: Francis)

In the illustration above, the 'benefit' or 'value' element of CBA/ SROI analyses is represented by practitioners' professional judgement in quantifying favourable or beneficial outcomes over time from expending resources now. It is crucial to note that while costs are easier to define, the benefit element incorporates both financial and non-financial measures formed from judgement (Millar and Hall, 2013). The use of CBA in the form of SROI in the departments represents an example of economic efficiency values being successfully inculcated into social work practice. Professional accountants recruited from other sectors were often not in a position to define benefit or value, as they lack the necessary expertise in social work. Instead, their primary role was to develop and maintain an accounting infrastructure within their respective organisations.

CBA was being used as an evaluator technique to ensure decisions are based on a 'balance' of competing factors, especially when managing resource constraints. At its most basic function, CBA is used to define the 'threshold' in gatekeeping. Choices to proceed with a course of action should only be made if benefits exceed costs. The purpose is to provide the discipline and legitimacy necessary to manage excess demands for services. Awareness amongst practitioners of what can realistically be achieved (benefits) within their finite budgets (costs) illustrates how gatekeeping operates, as a manager responsible for commissioning explained:

service managers being much more aware of costs and ... communicating [that to] social workers ... 'Don't go into care panel and ask for a fifty-two week highly specialist therapy, you know, you're not going to get one.' They might still come and ask for something very expensive but I think people are much more realistic and much more cost aware" (Warbridge: Sally)

The need to balance the benefits of care with its costs has particular relevance for gatekeeping decisions, as it enables professional judgements to be rejected on the basis of (purportedly scientific) cost 
calculations. The quote below from a budget manager illustrated how the use of CBA for gatekeeping can sometimes lead to harsh decisions on care:

I [try] to get the best out of the budget for as many children ... it really is trying to extract the most cost-effective price for the best quality provision ... spending $£ 5,000$ a week on a placement doesn't guarantee [that the teenagers in care are] going to end up in Eton, or ... Oxford [prestigious British educational establishments]" (Warbridge: Matthew)

The application of economic concepts in the quotes above symbolised a shift in the thought processes of managers, who actively sought to improve their management of limited financial resources. It is this response to adversity that actuates governmentality in a neo-liberal sense. Individuals take on new financial responsibilities and embrace certain accounting techniques to serve their specific organisational circumstances. Accounting enables priorities to be changed through the introduction of gatekeeping as a way of coping with excess demands on resources.

The use of accounting also enables financial responsibilities to be more clearly articulated by making any budget over or under-spending more visible and action-able from a distance. As experience in defining gatekeeping thresholds improves through usage, more formal structures are created. For instance, all three councils indicated that they had institutionalised procedures in place for social workers to bid for access to limited resources. Justification had to be made on the basis of economic principles, more commonly condensed in a 'business case', and the evaluation had to exceed subjectively defined thresholds before it could be funded, as a service manager elucidated.

[There is] a much greater expectation that we have a sound business case for when we want to use funding ... I need to be able to ... clearly demonstrate need, and ... efficiency for the council ... sometimes the business cases get turned down. Perhaps they haven't done sufficient work and I think that there's been a culture change. [Mexberry: William]

Ascribing budget responsibilities and embracing economic concepts in social work practice implies a 'cultural' shift towards an empirically oriented and financial approach to managing children's services departments. The use of accounting techniques had altered the way in which professional discretion in social work in the three departments was exercised, as there was now an expectation that business cases were developed and thresholds defined for care interventions. 


\section{Developing accounting infrastructure to support the management of financial responsibilities}

The use of CBA is premised on the establishment of a system to enable new accounting measurements or 'inscriptions' (Robson, 1992) to be stored in a database such as a management control system (MCS) for future use (e.g. Parton, 2008). Database systems were being developed across all social work departments visited.

The inscriptions take place principally through the codification and standardisation of behaviours and outcomes observed. Codification is the process by which information from front-line practitioners is transformed and fed into the MCS. Standardisation, which is a pre-requisite to facilitate benchmarking, specifies uniform ways in which social workers should codify information from the front line to the MCS. There was a number of ways in which MCS was used in the departments. One was to exert control over budgetary processes through the institutionalisation of accountability based on the consumption of financial resources, as a service manager explained:

there is a much greater emphasis ... at budget sufficiency ... I need to make sure I've got the money in the right place ... the online system allows me to know where the pressures are, and where I might want to put my flexibilities, more or less at the push of a button." (Mexberry: William)

The monitoring process worked through the creation of cost centres, which were then allocated real costs associated with a pre-defined social work activity. As the managers of devolved budgets were responsible for making decisions over care, they were said to 'own' the budgets or cost centres. Managers were then evaluated on the basis of variances between planned expenditure (defined using standardised costs or benchmarks) with actual (real) expenditure. A budget manager described how the system worked in their department:

We've got about 150 cost centres and ... 40 cost centre managers ... each cost centre under each manager ... would have the actual [expenditure] to-date ... the manager's projection, the variance to-date and then the movement from the previous period. [Warbridge: Fern]

The development of cost centres and the ascription of managerial responsibilities enhanced the visibility of senior management over areas experiencing financial pressure. As a result of the greater awareness, planning through MCS and budgets in particular could be used as a technique to facilitate the prioritisation of actions from afar. The quotes from accountants below illustrated these points:

we're ... identifying every single cost centre where we have a variance over $£ 10,000 \ldots$ we'll be meeting with the Head of Service and the 
Management Team to go through each line ... and identify what the issues are" (Mexberry: Kyle)

[Anonymous colleague] is very thorough ... she understands her budget ... Because ... it's a support service she's under a bit of [financial] pressure but she's also been able to attract social care funding from various sources for training ... most of the budgets at this level will be staff [costs in the form of salaries] so that's so important that we have the correct [figures]" (Deningford: Hugh)

As the quotes above makes clear, the devolution of budgets and the prioritisation of actions through the use of performance targets to manage pressure points were becoming more regular in the councils (e.g. Harris and Unwin, 2009). The responsibilities to manage costs mean that managers have to become more aware of the unit costs of each service provided, in addition to understanding the fluctuating nature of demands for some high cost services. An accountant below explained this new awareness of expensive care provision in some areas of the service and the actions it required:

we have a number of ... demand-led services and budgets from placements for children in social care, a variety of options around that and SEN [Special Educational Needs], transport on my schools ... they are things that could easily shoot you over budget very quickly ... five placements can cost you four grand $[£ 4,000]$ a week ... bang ... it's about making them [managers] more knowledgeable and knowing what their cost drivers are. [Warbridge: Tony]

The effect of financially motivated reprioritisations across all three councils drew managerial attention towards areas of acute resourcing pressures. Such attention did not always mean that the most expensive services would be reduced or jettisoned altogether. However, as attention is redirected towards dealing with resource constraints, this can leave other areas of significant but of non-financial need neglected. Organisational benefits accrued were not always evenly distributed amongst front-line practitioners and others within the councils. The cost savings attained appear to have primarily benefit politicians' austerity agendas, with energy and attention diverted towards the financial management at the expense of contact time with clients (Rogowski, 2010).

\section{Expanding what it means to be financially responsible}

An unexpected consequence of the embrace of economic values is that it had led one of the councils (Deningford) to embark on financial innovation to deal with cost pressures. For instance, several interviewees described how CBA and VFM affected their decisions on whether to 
retain in-house staff and capabilities or to outsource. The head of social work at the council stated that:

we've been doing value for money exercises on our services, ... and we do market testing so we're very open to saying 'Is there something in the external market that can do it better than us?' ... we've got a dreadful in-house direct services provision that is hugely expensive and the members [locally elected politicians] really supported us in challenging their costs and freeing up procurement rules" (Deningford: Helen)

The use of joint commissioning to minimise overheads, through the pooling of budgets between multiple neighbouring councils, reflects a financial innovation used to manage limited resources. These types of decisions are possible because accounting makes costs more visible to management and attributable to specific activities. When interviewed, a manager responsible for service procurement justified the council's decision to proceed with joint commissioning on the grounds that it helped to lower procurement costs through competition and standardisation of prices paid for services:

We all sat down [as a consortium of councils] and said '.. if we pool our strength together financially we can start calling the shots and have a more consistent approach to pricing and purchasing' so ... you don't have a situation where historically [the external providers] could charge me $30 \%$ more for the same placement ... they can't play us off now ... it has certainly saved [our council] hundreds of thousands of pounds in the ... eighteen months it has been running" (Deningford: Rebecca)

Such accounting-led and evidence-based decisions to innovate service provision represent another seemingly emancipatory outcome of the financial autonomy afforded through neo-liberal reforms. However, the reliance on financial innovation also reflects the extent to which the normalisation of social work as a 'business' (Harris, 2003, as cited in Rogowski, 2010, p. 146) has evolved.

\section{Reactions to the imposition of financial responsibilities}

Some managers and practitioners embraced accounting because they were confident that they did not have to always prioritise cost savings over the remit to protect clients, as the quote below demonstrates:

Good financial and fiscal management is correct ... but ... we've still got to make the right interventions (Warbridge: Matthew)

Across all councils interviewed, the level of acceptance and recognition of the role of accounting and MCS appeared to be widespread, at least amongst more senior management. Budgets, cost centres, variance 
analysis, CBA and its alternatives represented an increasingly prominent set of accounting vocabularies for social workers.

However, not all front-line practitioners accepted the ascription of financial responsibilities. Some front-line practitioners were broadly opposed to these developments and began to develop their own means of resistance, although the evidence suggested that this had little effect in terms of limiting the momentum of changes that were taking place. Some resisted the shift to a hybrid professional identity that necessitated financial management responsibilities, on the grounds of principle. Others accepted their new job identity for pragmatic reasons (e.g. Rogowski, 2011) because they wanted to protect their career prospects. The following practitioners' comments highlighted this dilemma:

that change of role for the social worker is not necessarily a good thing, it's probably de-skilling workers to some extent and ... you become like [a] guardian of services" (Deningford: Louis)

[Social workers are not] so innumerate that they cannot use the [accounting] tools ... I think ... there's some deeper issue underlying [sic] ... a small minority of managers [who] don't really see it as their role at heart" (Warbridge: Tony)

\section{Concluding thoughts}

This study illuminates the inculcation of financial responsibilities in social work through the lens of governmentality, examining microprocesses surrounding the application and usage of accounting techniques in three children's services departments in England. Building on research highlighting the encroachment of accounting in social work, the study contributes to knowledge in the field by demonstrating the value of accounting as an alternative perspective to examine the operationalisation of neo-liberal reforms in social work.

In particular, the findings demonstrate how accounting reorganises through a combination of socialisation processes (financial responsibility as a moral obligation, prioritisation of economic efficiency values and threats of exclusion), the application accounting techniques for gatekeeping and the expansion of infrastructure such as MCS and budgets. Accounting and its adopters (heads of services; accountants; team managers; front-line practitioners) facilitate the production of a world that is governable through the freedom of individuals who make (rational) decisions on the basis of accounting's calculative apparatus. The instillation of neo-liberal values that underpin the use of accounting privileges economic efficiency over those emphasising collectivism and organisational resilience.

However, the extent to which accounting is received or embraced within social work practice appears mixed. Despite accounting becoming ever more integrated into social work practice, not all are able to share 
in its emancipatory benefits. Some front-line practitioners in this study refused to wholeheartedly embrace neo-liberal values and accept the 'accountingisation' of their profession, a sentiment also echoed in Rogowski's (2011) research. The critical literature also notes the general sense of disillusionment amongst practitioners from the reorientation of social work as a business (Harris, 2003; Rogowski, 2010). Furthermore, there are also unintended consequences to the imposition of financial responsibilities, representing both opportunities for resistance and the possibilities of emancipation. Bracci and Llewellyn (2012) note that while some social work departments in their study were able to use accounting to enhance social work (people-changing), others struggled, viewing accounting as a functional instrument for 'people-processing' instead.

Despite such challenges, accounting has the potential to empower social workers in reasserting their epistemological claims over professional practice through innovation. A limitation of the study is that it does not go so far as to examine the robustness or scope (generalisability) of this emancipatory possibility. As the study's empirics draw on observations and personal recollections across three councils, its primary focus is on understanding the managerial use of accounting and reactions to its encroachment. But as with any major institutional change, the voices of those who are marginalised also need to be heard, though a brief discussion was offered. What needs to be recognised, however, is that accounting is 'equipping judgement systems that favour a neoliberal order' (Chiapello, 2017, p. 59) across the public sector. This makes it challenging to roll back its advance to a time of aplenty (Rogowski, 2010; Cummins, 2018). A pragmatic way forward would be to work with accounting and understand its possibilities for emancipation whilst being alert to its capacities for subjugation.

\section{Acknowledgements}

We would like to thank Durham University for providing a start-up grant to enable the empirical work to be carried out. We would also like to thank Carl Purcell for assistance with the empirical data collection. We would also like to thank the reviewers and editor for their constructive comments.

\section{Funding}

The authors Danny S. L. Chow and David Greatbatch would like to acknowledge the seed corn funding received from Durham University, which facilitated the data collection and transcriptions.

Conflict of Interest statement. None declared. 


\section{References}

Arnold, P. J. (1998) 'The limits of postmodernism in accounting history: The Decatur experience', Accounting, Organizations and Society, 23(7), pp. 665-84.

Bracci, E. (2014) 'Accountability and governance in social care: The impact of personalisation', Qualitative Research in Accounting \& Management, 11(2), pp. 111-28.

Bracci, E. and Llewellyn, S. (2012) 'Accounting and accountability in an Italian social care provider: Contrasting people-changing with people-processing approaches', Accounting, Auditing \& Accountability Journal, 25(5), pp. 806-34.

Chiapello, E. (2017) 'Critical accounting research and neoliberalism', Critical Perspectives on Accounting, 43, pp. 47-64.

Cooper, C. (2015) 'Entrepreneurs of the self: The development of management control since 1976', Accounting, Organizations and Society, 47, pp. 14-24.

Cummins, I. (2018) Poverty, Inequality and Social Work: The Impact of Neoliberalism and Austerity Policy on Welfare Provision, Bristol, Policy Press.

Ferguson, I. (2007) 'Increasing user choice or privatizing risk? The antinomies of personalization', British Journal of Social Work, 37(3), pp. 387-403.

Foucault, M. (1982) 'The subject and power', Critical Inquiry, 8(4), pp. 777-95.

Foucault, M. (1991) 'Governmentality', in Burchell, G. et al., (eds), The Foucault Effect: Studies in Governmentality (pp. 87-104). Chicago, University of Chicago Press.

Garrett, P. M. (2009) Transforming Children's Services: Social Work, Neoliberalism and the 'Modern' World. Maidenhead, Open University Press.

Hall, M. and Millo, Y. (2018) 'Choosing an accounting method to explain public policy: Social return on investment and UK non-profit sector policy', European Accounting Review, 27(2), pp. 339-61.

Harris, J. (2003) The Social Work Business. London, Routledge.

Harris, J. and Unwin, P. (2009) 'Performance management in modernised social work, chapter one', in Harris, J. and White, V. (eds), Modernising Social Work: Critical Considerations, Bristol, Policy Press.

Harris, J. and White, V. (eds) (2009) Modernising Social Work: Critical Considerations, Bristol, Policy Press.

Hood, C. (1991) 'A public management for all seasons?', Public Administration, 69(1), pp. 3-19.

Hood, C. (1995) 'The "new" public management in the 1980s: Variations on a theme', Accounting, Organizations and Society, 20(2-3), pp. 93-109.

Hopwood, A. G. (1983) 'On trying to study accounting in the contexts in which it operates', Accounting, Organizations and Society, 8(2-3), pp. 287-305.

Junne, J. (2018) 'Enabling accountability: An analysis of personal budgets for disabled people', Critical Perspectives on Accounting, 56, pp. 46-62.

Junne, J. and Huber, C. (2014) 'The risk of users' choice: Exploring the case of direct payments in German social care', Health, Risk \& Society, 16(7-8), pp. 631-48.

Kurunmäki, L. (2004) 'A hybrid profession - The acquisition of management accounting expertise by medical professionals', Accounting, Organizations and Society, 29(3-4), pp. 327-47.

Llewellyn, S. (1998a) 'Boundary work: Costing and caring in the social services', Accounting, Organizations and Society, 23(1), pp. 23-47. 
Llewellyn, S. (1998b) 'Pushing budgets down the line: ascribing financial responsibility in the UK social services', Accounting, Auditing \& Accountability Journal, 11(3), pp. 292-308.

Llewellyn, S. and Northcott, D. (2005) 'The average hospital', Accounting, Organizations and Society, 30(6), pp. 555-83.

Millar, R. and Hall, K. (2013) 'Social return on investment (SROI) and performance measurement', Public Management Review, 15(6), pp. 923-41.

Miller, P. and O'Leary, T. (1987) 'Accounting and the construction of the governable person', Accounting, Organizations and Society, 12(3), pp. 235-65.

Miller, P. and Rose, N. (1990) 'Governing economic life', Economy and Society, 19(1), pp. 1-31.

Munro, E. (2004) 'Learning to reduce risk in child protection', British Journal of Social Work, 40(4), pp. 1135-51.

Parton, N. (1994) "'Problematics of government”, (post) modernity and social work', The British Journal of Social Work, 24(1), pp. 9-32.

Parton, N. (2008) 'Changes in the form of knowledge in social work: From the "social" to the "informational", British Journal of Social Work, 38(2), pp. 253-69.

Power, M. and Laughlin, R. (1992) 'Critical theory and accounting', in Alveson, M. and Willmott, H. (eds), Critical Theory and Accounting, London, Sage Publications, pp. 113-35.

Raffnsøe, S., Mennicken, A. and Miller, P. (2019) 'The Foucault Effect in Organisation Studies', Organisation Studies, 40(2), pp. 155-82.

Rivest, M. P. and Moreau, N. (2015) 'Between emancipatory practice and disciplinary interventions: Empowerment and contemporary social normativity', British Journal of Social Work, 45(6), pp. 1855-70.

Robson, K. (1992) "Accounting numbers as "inscription": Action at a distance and the development of accounting', Accounting, Organizations and Society, 17(7), pp. 685-708.

Rogowski, S. (2010) Social Work: The Rise and Fall of a Profession? Bristol, Policy Press.

Rogowski, S. (2011) 'Managers, managerialism and social work with children and families: The deformation of a profession?', Practice, 23(3), pp. 157-67.

Rogowski, S. (2012) 'Social work with children and families: challenges and possibilities in the neo-liberal world', British Journal of Social Work, 42(5), pp. 921-40.

Wickramasinghe, D. (2015) 'Getting management accounting off the ground: Post-colonial neoliberalism in healthcare budgets', Accounting and Business Research, 45(3), pp. 323-55. 